\title{
SPECTRAL ANALYSIS OF THE SELECTED ACCELERATIONS AND ORBITAL ELEMENTS FOR THE GOCE SATELLITE ORBIT
}

\author{
Andrzej Bobojć \\ University of Warmia and Mazury \\ Institute of Geodesy \\ ul. Oczapowskiego 1, 10-950 Olsztyn, Poland \\ e-mail: altair@uwm.edu.pl
}

\begin{abstract}
The work contains the results of research of the simulated GOCE satellite orbit. For the 30-day orbit determination the Cowell numerical integration of the eighth order was used and the geopotential was described by means of the EGM96 model. The selected accelerations and the Keplerian elements were computed along this orbit. These accelerations included the satellite accelerations due to: the geopotential, the Earth tides and the ocean tides (the radial component for both), the gravitation of the Moon, the gravitation of the Sun, the gravitation of the Venus and the relativity effects.

The computed accelerations and Keplerian elements were treated as the input data for the DFT algorithm (Discrete Fourier Transform) to determine their spectral characteristics, i.e. the amplitude power spectral densities (PSD). Additionally, the averages and standard deviations were obtained for the aforementioned accelerations and Keplerian elements.

The numerous periodic components were identified. The characteristic resonances with the satellite orbital period, with the Earth's rotation period and with the Moon's synodic period were described.
\end{abstract}

Key words: GOCE satellite orbit, satellite accelerations, orbital elements, Fourier transform

\section{INTRODUCTION}

One of the ESA's missions is the Gravity Field and Steady - State Ocean Circulation Explorer Mission (GOCE). The GOCE mission was launched on 17 March 2009. The main result of this mission is to determine the geopotential model up to 200 degree and order of the spherical harmonic coefficients. The mentioned model will allow to obtain the gravity acceleration with an accuracy of $1 \mathrm{mGal}$ and to estimate of the geoid with an accuracy of $1 \mathrm{~cm}$. Such accuracies will be realized at spatial scales down to $100 \mathrm{~km}$ (ESA,1999; Drinkwater et al., 2003; Mégie and Readings, 2000; Rebhan et al., 2000).

A gradiometric satellite is a key component of the GOCE mission. This satellite will be put into almost circular and sun-synchronous orbit with an average altitude of about $250 \mathrm{~km}$ (ESA, 1999). The non-gravitational forces acting on the satellite will be compensated for by a drag-free control system (Drinkwater et al., 2003). To obtain of a data set of satellite laser ranging (SLR) measurements for controlling the satellite position, the GOCE satellite is equipped with the Laser Retro Reflector (LRR) in the form of a corner-cube array. The GOCE 
satellite is planned to provide two types of measurements: the gravity gradients (Satellite Gravity Gradiometry data - SGG data) and the high-low Satellite to Satellite tracking data (SST data). They will be obtained by two on-board devices: an electrostatic gravity gradiometer and a GPS/GLONASS receiver, respectively (Johannessen et al., 2003). Both the SGG data and the SST data will be subject of a joint inversion to estimate the Earth's gravity field model (Ditmar and Klees, 2002; Ditmar et al., 2003).

The knowledge of the satellite orbit is one of the important factors in the estimation of Earth's gravity field, taking into account the SGG and SST data. GPS measurements (SST data) are the basic data for the GOCE satellite orbit estimation. Advanced algorithms were prepared to determine the GOCE satellite orbit as a reduced-dynamic and a kinematic orbit solution (Bock et al., 2006; Visser et al.,2006).

The aim of this work was to determine the characteristic periodic components and their amplitudes and resonances for the selected accelerations and Keplerian elements of the GOCE orbit. Such results could be useful in an analysis of the GOCE orbit for the estimation of the Earth's gravity field model. The mentioned aim can be achieved by using the Fourier analysis for the satellite orbit. Similar research was performed by Baur and Grafarend (2005) to detect the characteristics of the rotational tensor of the GOCE orbit and by Visser et. al (2001) where the GOCE orbit perturbations were the subject of the Fourier transform to estimate the resonance effects in the process of the gravity field model determination.

\section{METHODOLGY}

To obtain the GOCE satellite orbit, the Cowell numerical integration method of the eighth order was used. The computed orbit was expressed with respect to the J2000.0 reference frame (Laing,1991, Anderson et al., 2002). This frame can be described in the following way: the origin at the Earth's mass centre, the X-axis is directed towards the mean vernal equinox of the standard epoch J2000.0 (at noon on January 1, 2000), the Z-axis points out from the Earth's mass centre along the Earth's mean rotational axis of the standard epoch J2000.0, the Y-axis completes the frame to the right-handed frame. The following initial elements of the GOCE satellite orbit were taken into the computation: the epoch: 54313.0 MJD, semi-major axis: $6634.7711 \mathrm{~km}$, eccentricity: 0.001, inclination: $96.5 \mathrm{deg}$., argument of perigee: 0.00 deg., right ascension of ascending node: $45.00 \mathrm{deg}$, mean anomaly: 0.00 deg., the orbital period $\mathrm{T}=89.64 \mathrm{~min}$. and the altitude: $250.00 \mathrm{~km}$ (ESA,1999). The computations were performed using the TOP package (Drożyner, 1995). The TOP package determines a satellite orbit in the Earth's gravity field taking into account selected perturbing forces. Several models were used to the orbit computation. The EGM96 model (Lemoine et al.,1998) was taken for the geopotential. The Earth and ocean tides were modelled by the MERIT Standards (Melbourne et al. 1983). Both, the IAU1976 Theory of Precession and the IAU1980 Theory of Nutation (the Wahr nutation) were included to the computation. The model describing the relativity effects originated from the TOP package. Additionally, the following data were taken into the computation: the Sun, Moon and planetary ephemerides DE200/L200 (epoch J2000.0). The pole coordinates were equal to zero.

It was assumed that the GOCE satellite motion is determined by the geopotential and by the following forces: the gravitation of the Moon, the gravitation of the Sun, the gravitation of the planets, the Earth tides and the ocean tides. Additionally, the relativity effects were taken into account in the satellite motion model. The adopted relativity effects result from the Schwarzschild metrics which reflects the influence of a gravity field with spherical symmetry.

A 30-day arc of the GOCE satellite orbit with an integration step $1 \mathrm{~s}$ was obtained. The chosen satellite accelerations due to the mentioned above forces and the selected Keplerian 
elements (semi-major axis, eccentricity, inclination, argument of perigee, right ascension of ascending node) were computed along this orbit.

Using the obtained accelerations and Keplerian elements, the Discrete Fourier Transform (DFT) was performed to compute the corresponding amplitude Power Spectral Densities (PSD). The general formula describing the DFT has the following form:

$$
X_{k}=\sum_{n=0}^{N-1} x_{n} e^{-2 \pi f_{k} s n}=\sum_{n=0}^{N-1} x_{n}\left[\cos \left(2 \pi f_{k} s n\right)-i \sin \left(2 \pi f_{k} s n\right)\right]
$$

where:

$X_{k}$ - an output data; a complex series in the frequency domain $(k=0,1, N-1), x_{n}-$ an input data; a complex series in the time domain $(n=0,1, N-1), N$ - total number of elements of the $X_{k}$ series and of the $x_{n}$ series, $f_{k}$ - the frequency corresponding to the given element of the $X_{k}$ series, $s-$ a sampling interval. In this case, the input data included the computed accelerations and Keplerian elements as the time series of real type. The determined spectra (amplitude PSD) show the distribution of the amplitude of given acceleration or Keplerian element in the frequency domain. This amplitude $A_{k}$ was obtained by means of the following expression:

$$
A_{k}=\frac{\sqrt{\left(\sum_{n=0}^{N-1} x_{n} \cos \left(2 \pi f_{k} s n\right)\right)^{2}+\left(\sum_{n=0}^{N-1} x_{n} \sin \left(2 \pi f_{k} s n\right)\right)^{2}}}{N} .
$$

The frequency $f_{k}$, which corresponds to the amplitude $A_{k}$, was computed using the formula:

$$
f_{k}=\frac{k}{N} \frac{1}{s}
$$

where the sampling interval $s$ is equal to 4 seconds. Taking this into account and the 30 -day arc of simulated orbit, the total number $N$ of elements of given time series is equal to 648000 . However, each of the obtained spectras consists of 324002 points. It is caused by the spectrum symmetry because the input data included the real-valued time series.

\section{RESULTS FOR SELECTED ACCELERATIONS}

The presented below graphs show the determined amplitude PSD of the given acceleration and allow to identify the periodic components as the numerous peaks over the curved reference line, (i.e. over the Fourier background).

Figure 1 presents the amplitude PSD of the satellite acceleration generated by the geopotential. The visible dominating periodic components are related with the satellite orbital period. They have the amplitudes of about $7.44 \mathrm{E}-03,7.12 \mathrm{E}-03,6.16 \mathrm{E}-03 \mathrm{~m} / \mathrm{s}^{2}$ and the periods of about $89.44 \mathrm{~min} ., 89.63 \mathrm{~min} ., 44.77 \mathrm{~min}$., respectively (Table 1). The group of many periodic components occurs in the frequency range from $\sim 3 \mathrm{E}-04$ to $\sim 3 \mathrm{E}-02 \mathrm{~Hz}$ (Fig.1).

During the 30-day interval, the considered acceleration oscillated around the average about $9.06 \mathrm{~m} / \mathrm{s}^{2}$ with the standard deviation $\sim 0.02 \mathrm{~m} / \mathrm{s}^{2}$ (Table 1). 


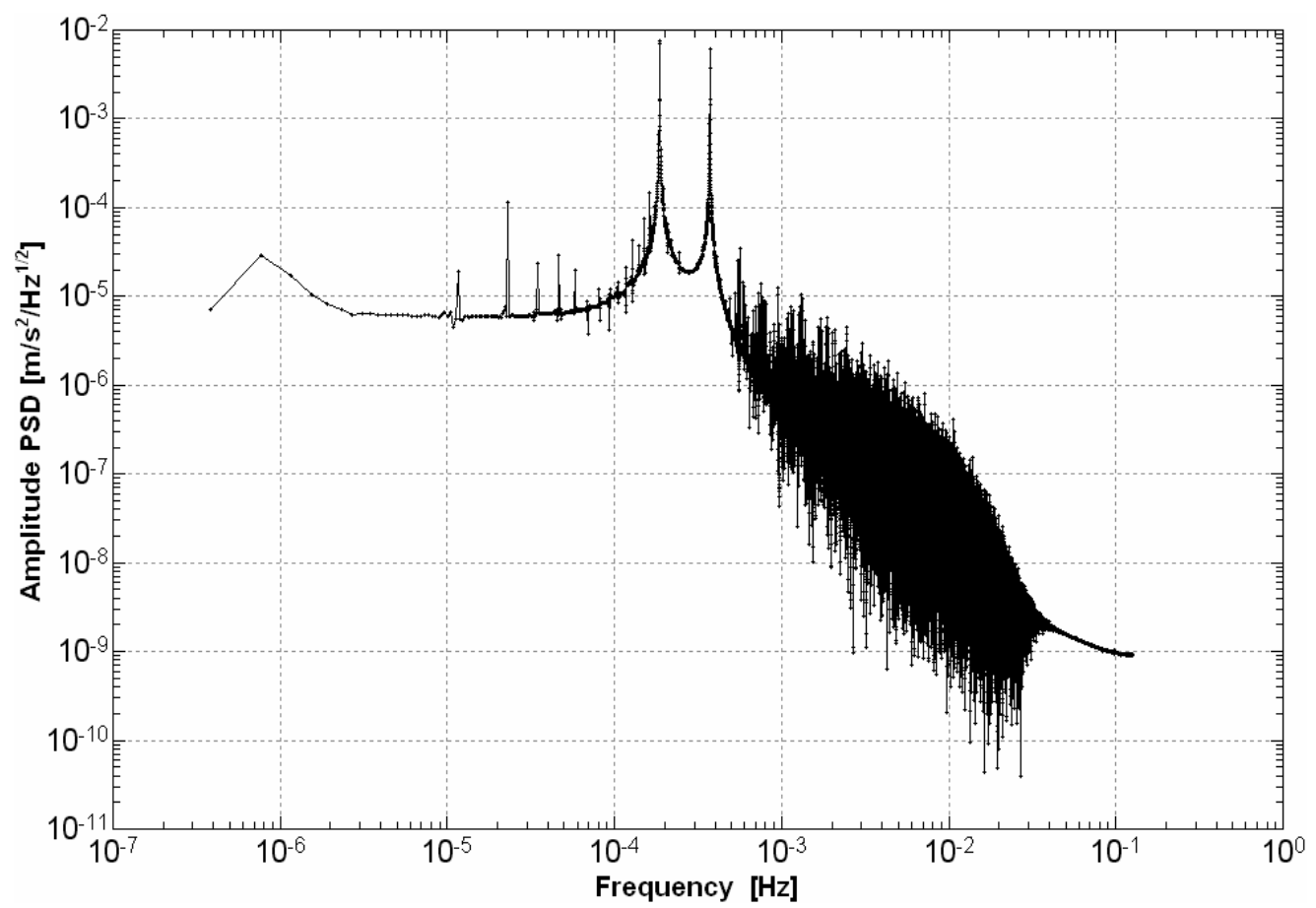

Fig. 1. Amplitude PSD of the satellite acceleration due to the geopotential for the 30 day orbital arc. Sampling interval: 4 seconds.

\begin{tabular}{|c|c|c|}
\hline Amplitude $\left[\mathrm{m} / \mathrm{s}^{2}\right]$ & Frequency $[\mathrm{Hz}]$ & Period \\
\hline $7.4415 \mathrm{E}-03$ & $1.8634 \mathrm{E}-04$ & $89.4410 \mathrm{~min}$. \\
\hline $7.1179 \mathrm{E}-03$ & $1.8596 \mathrm{E}-04$ & $89.6266 \mathrm{~min}$. \\
\hline $6.1570 \mathrm{E}-03$ & $3.7230 \mathrm{E}-04$ & $44.7668 \mathrm{~min}$. \\
\hline $3.6944 \mathrm{E}-03$ & $3.7191 \mathrm{E}-04$ & $44.8133 \mathrm{~min}$. \\
\hline $1.6223 \mathrm{E}-04$ & $1.9753 \mathrm{E}-04$ & $84.3750 \mathrm{~min}$. \\
\hline $1.4780 \mathrm{E}-04$ & $1.6281 \mathrm{E}-04$ & $1.7062 \mathrm{~h}$ \\
\hline $1.1606 \mathrm{E}-04$ & $2.3148 \mathrm{E}-05$ & $12.0000 \mathrm{~h}$ \\
\hline \multicolumn{2}{|c|}{ Average: $9.0621 \mathrm{~m} / \mathrm{s}^{2}$ sigma: $1.8919 \mathrm{E}-02 \mathrm{~m} / \mathrm{s}^{2}$} \\
\hline
\end{tabular}

Table 1: Selected amplitudes, frequencies and periods of the satellite acceleration due to the geopotential and the average and sigma of this acceleration in the time domain.

The amplitude PSD of the satellite acceleration caused by the radial component of the Earth tides is given in Figure 2. In this case, the strongest components are characterized by the amplitudes close to $8.07 \mathrm{E}-08,4.97 \mathrm{E}-08,3.70 \mathrm{E}-08 \mathrm{~m} / \mathrm{s}^{2}$ and the periods of about 15.0 days, 44.77 min., 44.81 min., respectively (Table 2 ).

For the radial component of the acceleration caused by the Earth tides, the average $1.43 \mathrm{E}-07 \mathrm{~m} / \mathrm{s}^{2}$ from the 30 -day orbital arc is smaller than the corresponding standard deviation $\sim 1.70 \mathrm{E}-07 \mathrm{~m} / \mathrm{s}^{2}$ because of the changing sign of this component. The positive sign means the direction of action radially upward. 


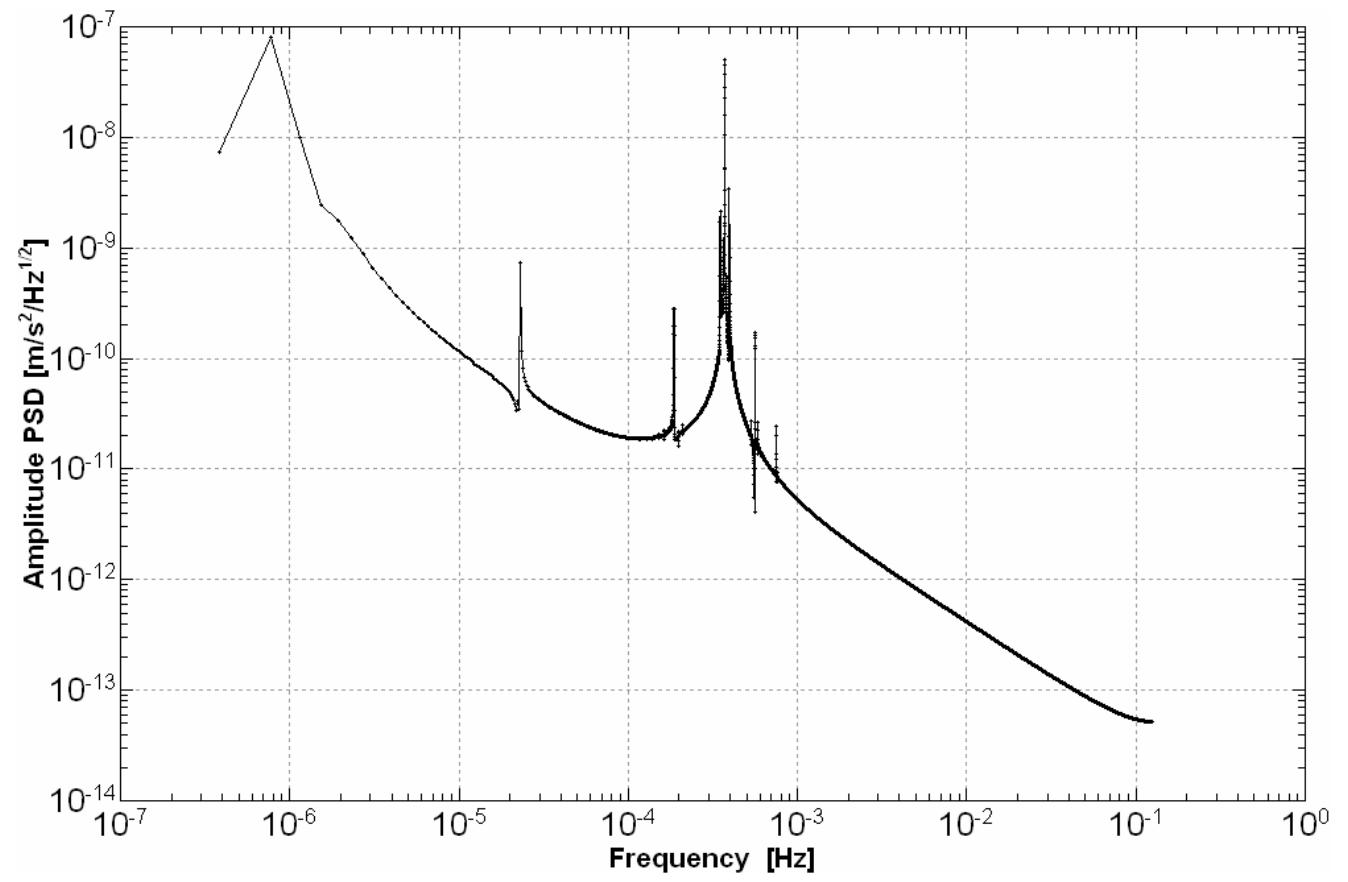

Fig. 2. Amplitude PSD of the radial component of the satellite acceleration due to the Earth tides for the 30 day orbital arc. Sampling interval: 4 seconds.

\begin{tabular}{|c|c|c|}
\hline Amplitude $\left[\mathrm{m} / \mathrm{s}^{2}\right]$ & Frequency $[\mathrm{Hz}]$ & Period \\
\hline $8.0747 \mathrm{E}-08$ & $7.7160 \mathrm{E}-07$ & 15.0000 days \\
\hline $4.9661 \mathrm{E}-08$ & $3.7230 \mathrm{E}-04$ & $44.7668 \mathrm{~min}$. \\
\hline $3.6981 \mathrm{E}-08$ & $3.7191 \mathrm{E}-04$ & $44.8133 \mathrm{~min}$. \\
\hline $3.3801 \mathrm{E}-09$ & $3.9545 \mathrm{E}-04$ & $42.1463 \mathrm{~min}$. \\
\hline $2.1507 \mathrm{E}-09$ & $3.4915 \mathrm{E}-04$ & $47.7348 \mathrm{~min}$. \\
\hline $7.2570 \mathrm{E}-10$ & $2.3148 \mathrm{E}-05$ & $12.0000 \mathrm{~h}$ \\
\hline $2.7818 \mathrm{E}-10$ & $1.8596 \mathrm{E}-04$ & $89.6266 \mathrm{~min}$. \\
\hline Average: $1.4344 \mathrm{E}-07 \mathrm{~m} / \mathrm{s}^{2}$ sigma: $1.6961 \mathrm{E}-07 \mathrm{~m} / \mathrm{s}^{2}$ \\
\hline
\end{tabular}

Table 2: Selected amplitudes, frequencies and periods of the radial component of the satellite acceleration due to the Earth tides and its average and sigma in the time domain.

The spectral characteristics of the radial component of satellite acceleration induced by the ocean tides is given in Figure 3. The largest periodic components have the amplitudes

$9.48 \mathrm{E}-09, \sim 9.31 \mathrm{E}-09, \sim 7.10 \mathrm{E}-09 \mathrm{~m} / \mathrm{s}^{2}$ and the periods about 4.80 hours, $38.74 \mathrm{~min} ., 22.42$ min. (Table 3). There are many periodic components in the frequency range from $\sim 1 \mathrm{E}-04$ to $\sim 1.1 \mathrm{E}-03 \mathrm{~Hz}$ (Figure 3). In this case, the average is equal to about $-1.0 \mathrm{E}-09 \mathrm{~m} / \mathrm{s}^{2}$ and the standard deviation (sigma) is near a value of $6.6 \mathrm{E}-08 \mathrm{~m} / \mathrm{s}^{2}$ (Table 3 ).

Similarly as in the case of the acceleration due the Earth tides, the absolute value of average is smaller than the absolute value of sigma, which is caused by the change of sign of the acceleration due to the ocean tides along the 30-day orbital arc. If the sign is negative then the action direction is towards the Earth's mass centre. 


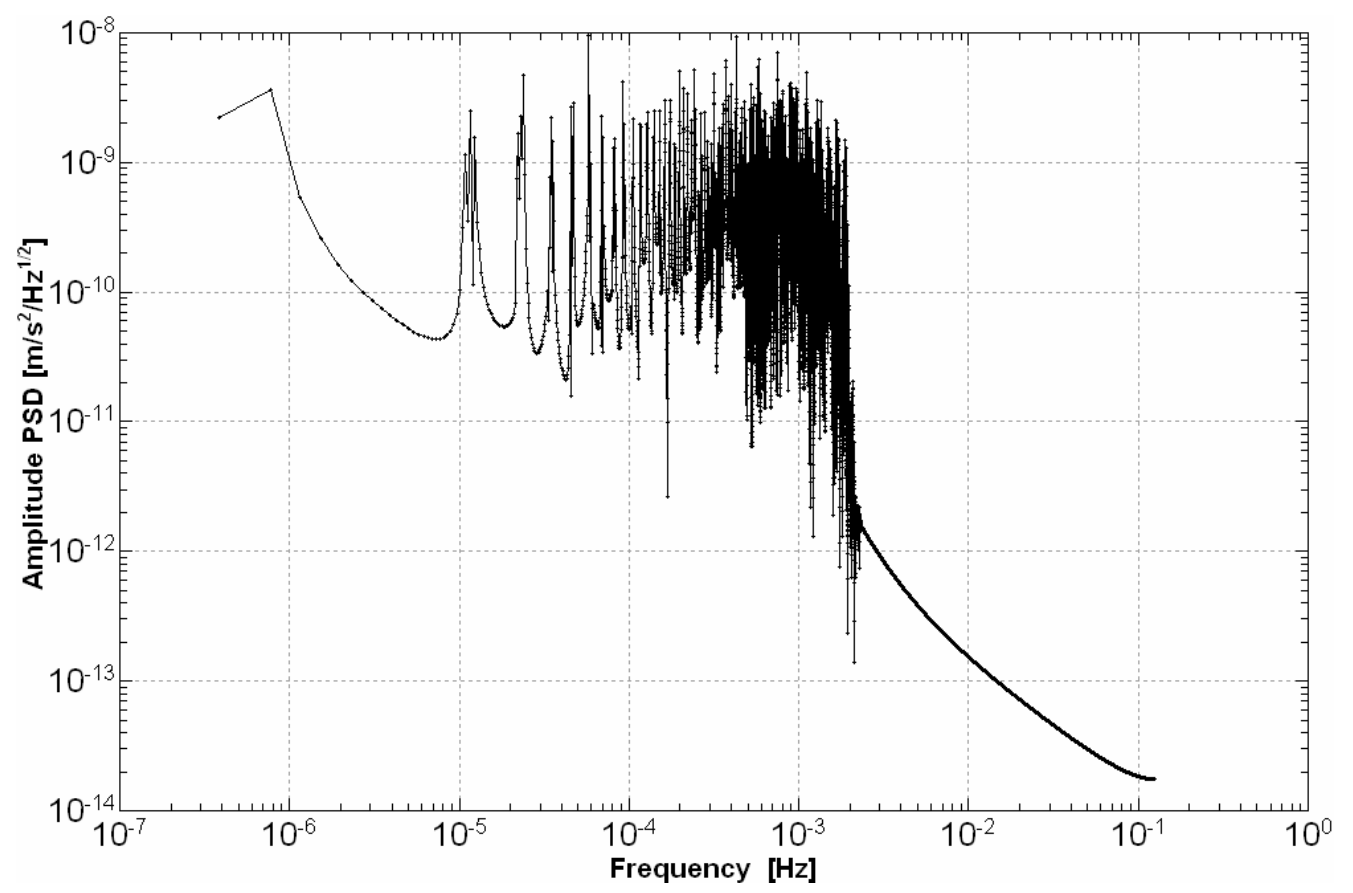

Fig. 3. Amplitude PSD of the radial component of the satellite aceleration due to the ocean tides for the 30 day orbital arc. Sampling interval: 4 seconds.

\begin{tabular}{|c|c|c|}
\hline Amplitude $\left[\mathrm{m} / \mathrm{s}^{2}\right]$ & Frequency $[\mathrm{Hz}]$ & Period \\
\hline $9.4832 \mathrm{E}-09$ & $5.7870 \mathrm{E}-05$ & $4.8000 \mathrm{~h}$ \\
\hline $9.3122 \mathrm{E}-09$ & $4.3017 \mathrm{E}-04$ & $38.7444 \mathrm{~min}$. \\
\hline $7.0993 \mathrm{E}-09$ & $7.4344 \mathrm{E}-04$ & $22.4183 \mathrm{~min}$. \\
\hline $6.2417 \mathrm{E}-09$ & $5.8218 \mathrm{E}-04$ & $28.6282 \mathrm{~min}$. \\
\hline $6.0411 \mathrm{E}-09$ & $3.7307 \mathrm{E}-04$ & $44.6742 \mathrm{~min}$. \\
\hline $5.3648 \mathrm{E}-09$ & $5.7060 \mathrm{E}-04$ & $29.2089 \mathrm{~min}$. \\
\hline $5.1329 \mathrm{E}-09$ & $2.4306 \mathrm{E}-04$ & $68.5714 \mathrm{~min}$. \\
\hline Average: $-1.0095 \mathrm{E}-09 \mathrm{~m} / \mathrm{s}^{2}$ sigma: $6.6152 \mathrm{E}-08 \mathrm{~m} / \mathrm{s}^{2}$ \\
\hline
\end{tabular}

Table 3: Selected amplitudes, frequencies and periods of the radial component of the satellite acceleration due to the ocean tides and its average and sigma in the time domain.

The amplitude PSD for the acceleration generated by the gravitation of the Moon is illustrated in Figure 4. For this acceleration the most important components are characterized by the amplitudes near values: $6.52 \mathrm{E}-08,5.46 \mathrm{E}-08,4.58 \mathrm{E}-08 \mathrm{~m} / \mathrm{s}^{2}$ and by the periods near values: 15.0 days, $44.77 \mathrm{~min}$., $44.86 \mathrm{~min}$., respectively (Table 4). The last second period values are close to half the satellite orbital period.

The average for the acceleration due to the gravitation of the Moon is equal to about $7.48 \mathrm{E}-07 \mathrm{~m} / \mathrm{s}^{2}$ with the standard deviation $1.78 \mathrm{E}-07 \mathrm{~m} / \mathrm{s}^{2}$ along the simulated 30 -day orbital $\operatorname{arc~(Table~4).~}$ 


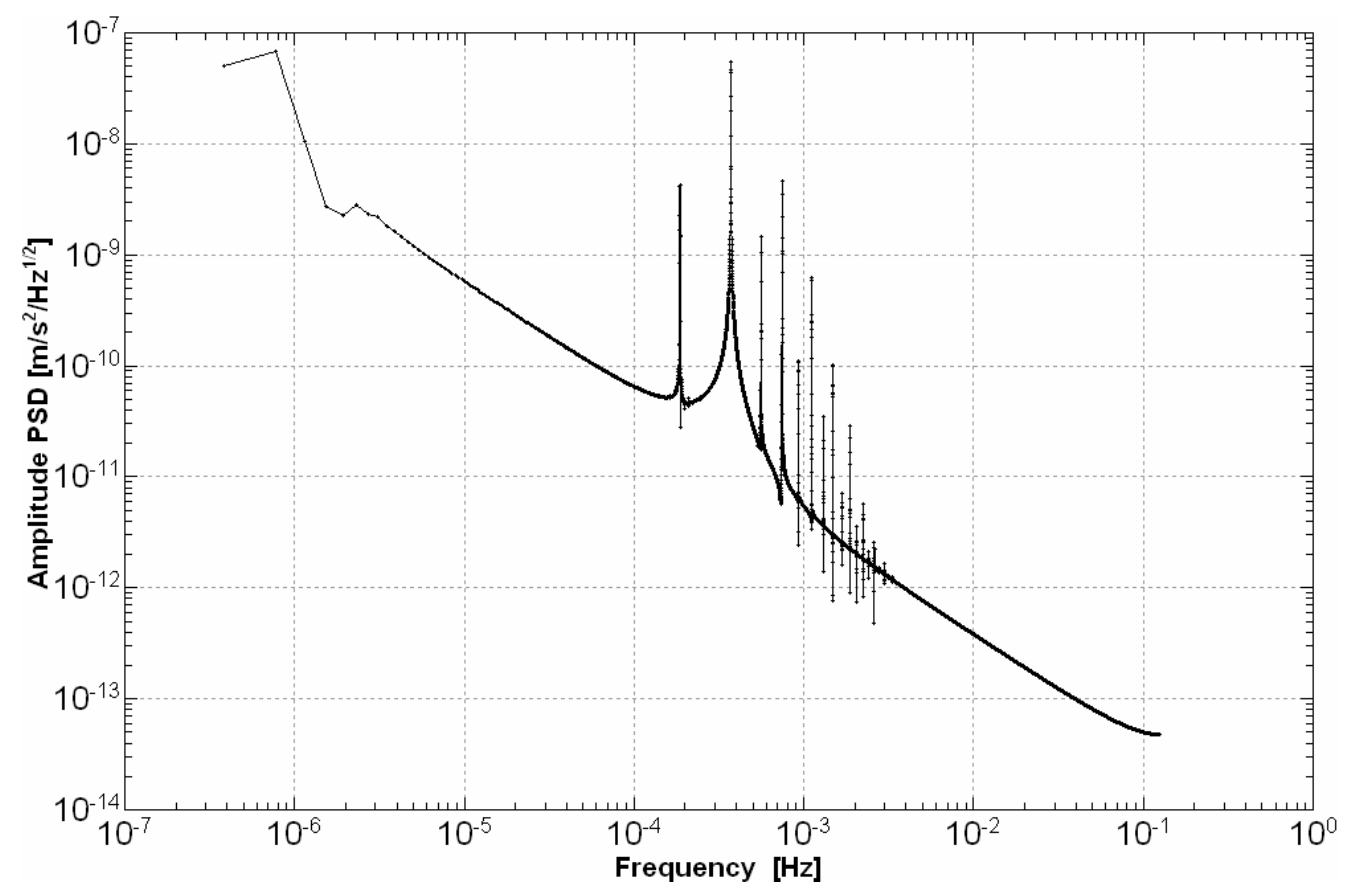

Fig. 4. Amplitude PSD of the satellite acceleration due to the gravitation of the Moon for the 30 day orbital arc. Sampling interval: 4 seconds.

\begin{tabular}{|c|c|c|}
\hline Amplitude $\left[\mathrm{m} / \mathrm{s}^{2}\right]$ & Frequency $[\mathrm{Hz}]$ & Period \\
\hline $6.5188 \mathrm{E}-08$ & $7.1606 \mathrm{E}-07$ & 15.0000 days \\
\hline $5.4620 \mathrm{E}-08$ & $3.7230 \mathrm{E}-04$ & $44.7668 \mathrm{~min}$. \\
\hline $4.5790 \mathrm{E}-08$ & $3.7153 \mathrm{E}-04$ & $44.8598 \mathrm{~min}$. \\
\hline $4.6668 \mathrm{E}-09$ & $7.4421 \mathrm{E}-04$ & $22.3950 \mathrm{~min}$. \\
\hline $4.2555 \mathrm{E}-09$ & $1.8634 \mathrm{E}-04$ & $89.4410 \mathrm{~min}$. \\
\hline $4.1818 \mathrm{E}-09$ & $1.8557 \mathrm{E}-04$ & $89.8129 \mathrm{~min}$. \\
\hline 2.8422E-09 & $2.3148 \mathrm{E}-06$ & 5.0000 days \\
\hline Average: $7.4803 \mathrm{E}-07 \mathrm{~m} / \mathrm{s}^{2}$ sigma: $1.7845 \mathrm{E}-07 \mathrm{~m} / \mathrm{s}^{2}$ \\
\hline
\end{tabular}

Table 4: Selected amplitudes, frequencies and periods of the satellite acceleration due to the gravitation of the Moon. At the last line, the average and sigma of this acceleration in the time domain.

The components with the periods $\sim 44.77 \mathrm{~min} ., \sim 44.81 \mathrm{~min}$, $\sim 44.72 \mathrm{~min}$., close to half the satellite orbital period, dominate in Figure 5, which presents the amplitude PSD for the acceleration due to the gravitation of the Sun. The corresponding amplitudes for the mentioned periods are near values $2.22 \mathrm{E}-09,8.48 \mathrm{E}-10,4.01 \mathrm{E}-10 \mathrm{~m} / \mathrm{s}^{2}$ (Table 5). Two other components clearly distinguish in Figure 5 . They have the periods about $89.44 \mathrm{~min}$. and $22.38 \mathrm{~min}$. (Table 5). In presenting case, the averaged acceleration is equal to $\sim 2.58 \mathrm{E}-07$ $\mathrm{m} / \mathrm{s}^{2}$ and the standard deviation is $\sim 3.62 \mathrm{E}-09 \mathrm{~m} / \mathrm{s}^{2}$. Thus, the average for the acceleration generated by the Sun's gravitation is smaller than the corresponding value for the Moon's gravitation, but both values have the same order of magnitude. 


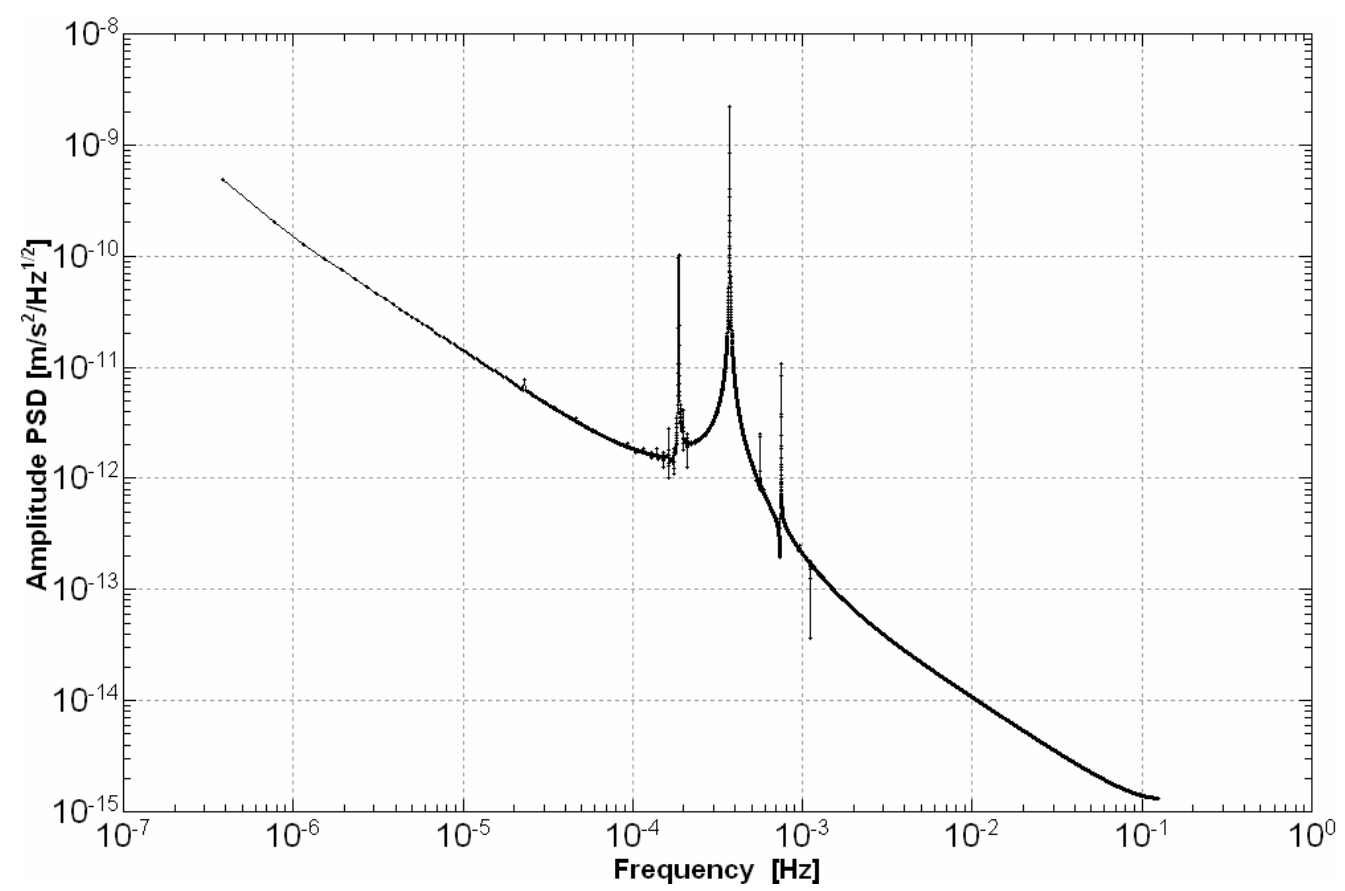

Fig. 5. Amplitude PSD of the satellite acceleration due to the gravitation of the Sun for the 30 day orbital arc. Sampling interval: 4 seconds.

\begin{tabular}{|c|c|c|}
\hline Amplitude $\left[\mathrm{m} / \mathrm{s}^{2}\right]$ & Frequency $[\mathrm{Hz}]$ & Period \\
\hline $2.2174 \mathrm{E}-09$ & $3.7230 \mathrm{E}-04$ & $44.7668 \mathrm{~min}$. \\
\hline $8.4779 \mathrm{E}-10$ & $3.7191 \mathrm{E}-04$ & $44.8133 \mathrm{~min}$. \\
\hline $4.0082 \mathrm{E}-10$ & $3.7268 \mathrm{E}-04$ & $44.7205 \mathrm{~min}$. \\
\hline $1.0291 \mathrm{E}-10$ & $1.8634 \mathrm{E}-04$ & $89.4410 \mathrm{~min}$. \\
\hline $9.6258 \mathrm{E}-11$ & $1.8596 \mathrm{E}-04$ & $89.6266 \mathrm{~min}$. \\
\hline $1.0676 \mathrm{E}-11$ & $7.4460 \mathrm{E}-04$ & $22.3834 \mathrm{~min}$. \\
\hline 8.4758E-12 & $7.4421 \mathrm{E}-04$ & $22.3950 \mathrm{~min}$. \\
\hline Average: $2.5776 \mathrm{E}-07 \mathrm{~m} / \mathrm{s}^{2}$ sigma: $3.6242 \mathrm{E}-09 \mathrm{~m} / \mathrm{s}^{2}$ \\
\hline
\end{tabular}

Table 5: Selected amplitudes, frequencies and periods of the satellite acceleration due to the gravitation of the Sun. At the last line, the average and sigma of this acceleration in the time domain.

The amplitude PSD for the acceleration due to the gravitation of the Venus is given in Figure 6 . The component $\sim 44.77$ min. (amplitude about 3.34E-13) clearly dominates in the spectrum. Three components, i.e. $\sim 89.63 \mathrm{~min} ., \sim 89.44 \mathrm{~min}$. and $\sim 22.40 \mathrm{~min}$. (amplitudes about: 1.34E-14, 1.02E-14, 6.52E-15, respectively) can be also distinguished (Table 6).

For the considered acceleration simulated along the 30-day orbital arc, the average is equal to only about $2.50 \mathrm{E}-11 \mathrm{~m} / \mathrm{s}^{2}$ and the standard deviation is $\sim 2.54 \mathrm{E}-12 \mathrm{~m} / \mathrm{s}^{2}$ (Table 6 ). 


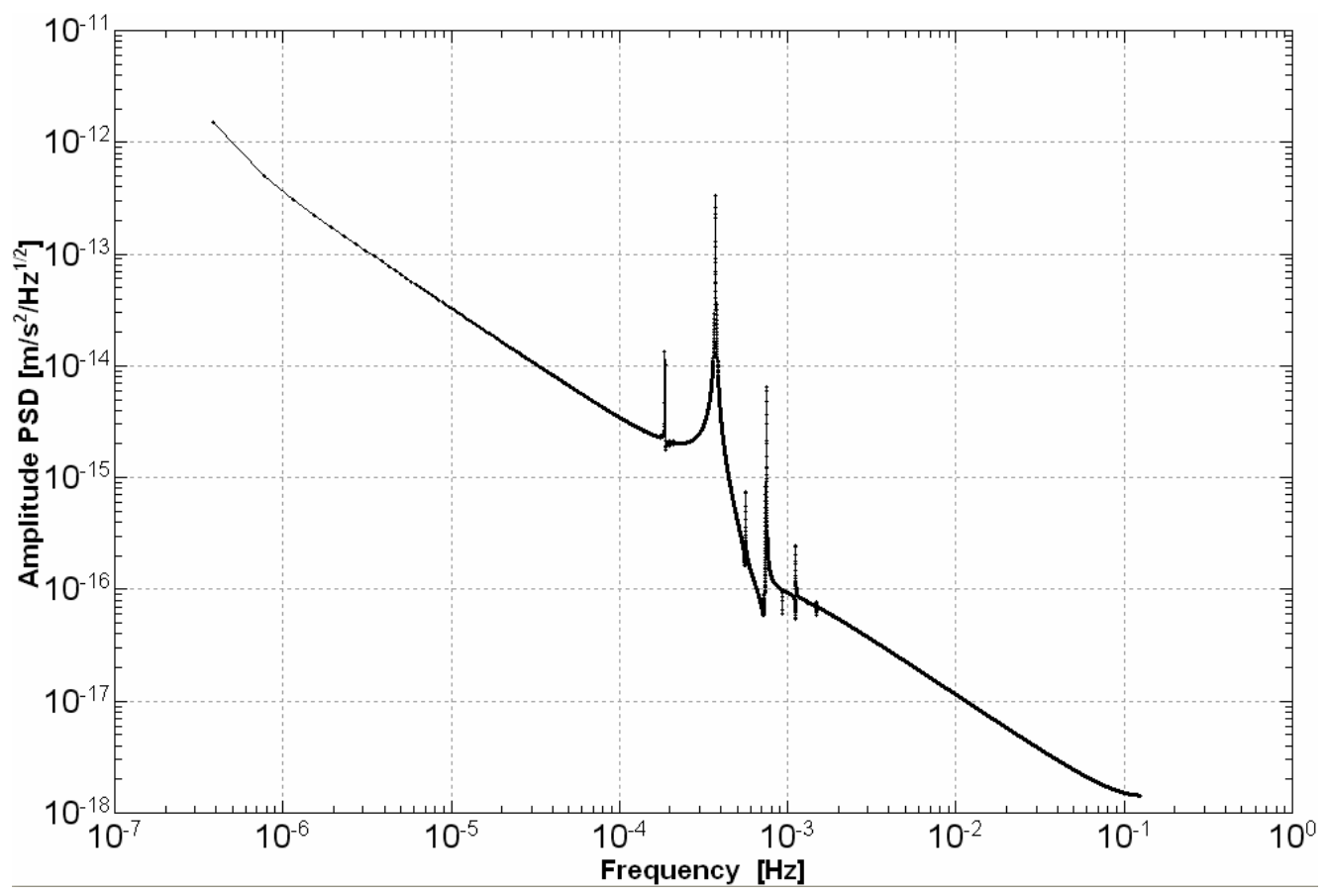

Fig. 6. Amplitude PSD of the satellite acceleration due to the gravitation of the Venus for the 30 day orbital arc. Sampling interval: 4 seconds.

\begin{tabular}{|c|c|c|}
\hline Amplitude $\left[\mathrm{m} / \mathrm{s}^{2}\right]$ & Frequency $[\mathrm{Hz}]$ & Period \\
\hline $3.3359 \mathrm{E}-13$ & $3.7230 \mathrm{E}-04$ & $44.7668 \mathrm{~min}$. \\
\hline $1.3442 \mathrm{E}-14$ & $1.8596 \mathrm{E}-04$ & $89.6266 \mathrm{~min}$. \\
\hline $1.0220 \mathrm{E}-14$ & $1.8634 \mathrm{E}-04$ & $89.4410 \mathrm{~min}$. \\
\hline $6.5228 \mathrm{E}-15$ & $7.4421 \mathrm{E}-04$ & $22.3950 \mathrm{~min}$. \\
\hline $7.4064 \mathrm{E}-16$ & $5.5864 \mathrm{E}-04$ & $29.8343 \mathrm{~min}$. \\
\hline $2.4387 \mathrm{E}-16$ & $1.1169 \mathrm{E}-03$ & $14.9223 \mathrm{~min}$. \\
\hline $7.6398 \mathrm{E}-17$ & $1.4896 \mathrm{E}-03$ & $11.1888 \mathrm{~min}$. \\
\hline Average: $2.5002 \mathrm{E}-11 \mathrm{~m} / \mathrm{s}^{2}$ sigma: $2.5431 \mathrm{E}-12 \mathrm{~m} / \mathrm{s}^{2}$ \\
\hline
\end{tabular}

Table 6: Selected amplitudes, frequencies and periods of the satellite acceleration due to the gravitation of the Venus. At the last line, the average and sigma of this acceleration in the time domain.

Figure 7 contains the amplitude PSD for the satellite acceleration under the influence of the relativity effects. The three largest components are characterized by the amplitudes near values $1.99 \mathrm{E}-11,8.21 \mathrm{E}-12,4.57 \mathrm{E}-13 \mathrm{~m} / \mathrm{s}^{2}$ and by the periods $89.441 \mathrm{~min}$., $\sim 44.77 \mathrm{~min} ., \sim$ $84.38 \mathrm{~min}$. (Table 7). Besides, the component with the amplitude about $2.06 \mathrm{E}-13 \mathrm{~m} / \mathrm{s}^{2}$ and with the period 12.00 hours distinguishes in Figure 7. The average of acceleration due to the relativity effects for the 30-day arc is equal to $\sim 1.82 \mathrm{E}-08 \mathrm{~m} / \mathrm{s}^{2}$ and its standard deviation is $\sim$ $4.36 \mathrm{E}-11 \mathrm{~m} / \mathrm{s}^{2}$. 


\begin{tabular}{|c|c|c|}
\hline Amplitude $\left[\mathrm{m} / \mathrm{s}^{2}\right]$ & Frequency $[\mathrm{Hz}]$ & Period \\
\hline $1.9955 \mathrm{E}-11$ & $1.8634 \mathrm{E}-04$ & $89.4410 \mathrm{~min}$. \\
\hline $8.2134 \mathrm{E}-12$ & $3.7230 \mathrm{E}-04$ & $44.7668 \mathrm{~min}$. \\
\hline $4.5723 \mathrm{E}-13$ & $1.9753 \mathrm{E}-04$ & $84.3750 \mathrm{~min}$. \\
\hline $3.2559 \mathrm{E}-13$ & $1.6281 \mathrm{E}-04$ & $102.3697 \mathrm{~min}$. \\
\hline $2.0587 \mathrm{E}-13$ & $2.3148 \mathrm{E}-05$ & $12.0000 \mathrm{~h}$ \\
\hline Average: $1.8204 \mathrm{E}-08 \mathrm{~m} / \mathrm{s}^{2}$ sigma: $4.3651 \mathrm{E}-11 \mathrm{~m} / \mathrm{s}^{2}$ \\
\hline
\end{tabular}

Table 7: Selected amplitudes, frequencies and periods of the satellite acceleration due to the relativity effect. At the last line, the average and sigma of this acceleration in the time domain.

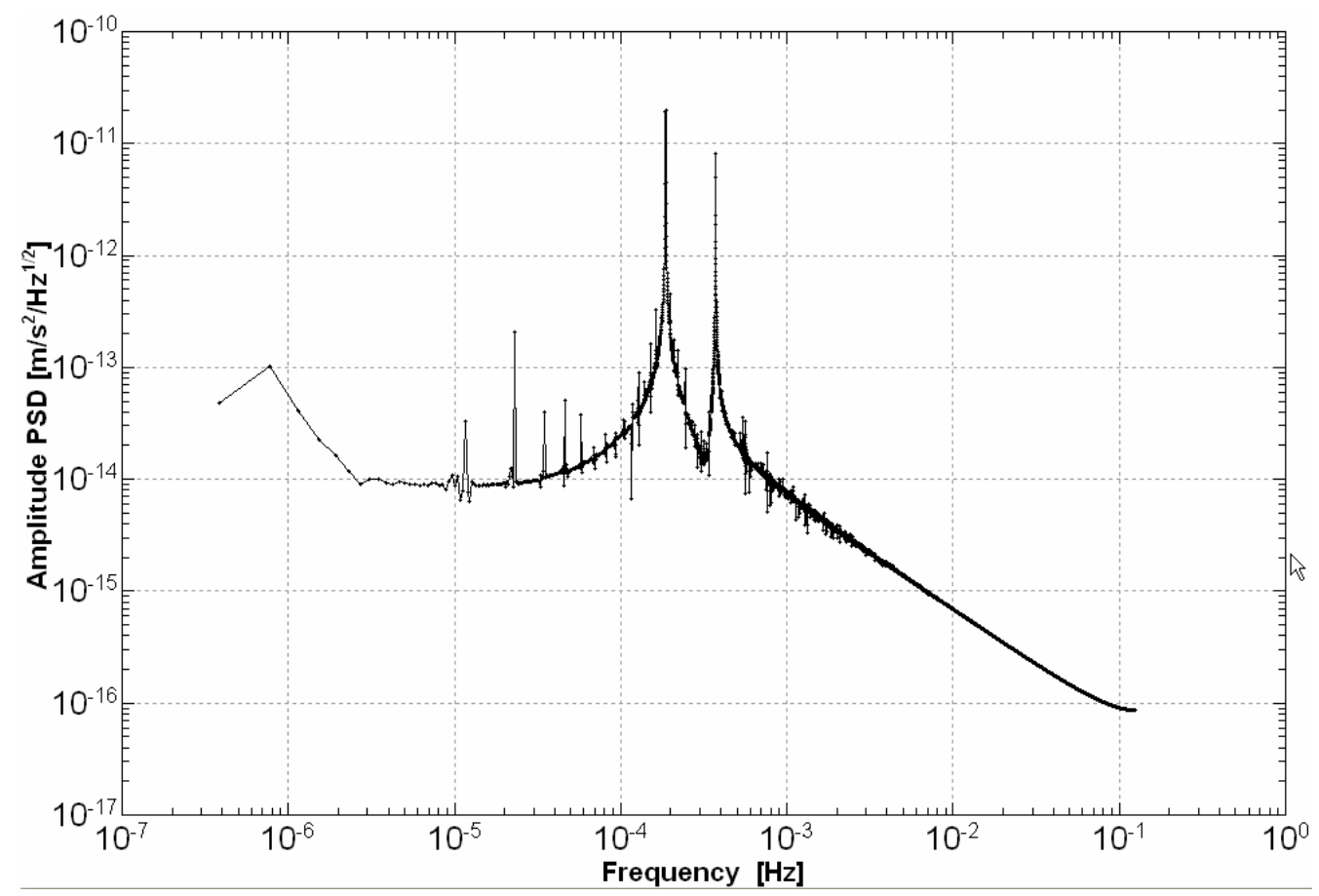

Fig. 7. Amplitude PSD of the satellite acceleration due to the relativity effects for the 30 day orbital arc. Sampling interval: 4 seconds.

In Table 8, the noticed resonances of the periodic components of the aforementioned accelerations are collected. These resonances were obtained with respect to three periods: the 30-day period (close to the Moon's synodic period), the Earth's rotation period and the period $86.441 \mathrm{~min}$. (close to the satellite orbital period). The presented resonances are placed between 1:1 and 1:225. For the component (with the period $12.80 \mathrm{~min}$.) of the acceleration due to the gravitation of the Moon, the half resonance 1:112.5 with respect to the Earth's 


\begin{tabular}{|c|c|c|c|}
\hline \multirow{2}{*}{$\begin{array}{c}\text { Acceleration } \\
\text { due to }\end{array}$} & $\begin{array}{c}|c| \\
\text { the 30-day } \\
\text { period }\end{array}$ & the Earth's rotation period & the 89.441 min. period \\
\hline the geopotential & $1: 2$ & $1: 1,1: 2,1: 3,1: 4,1: 5,1: 13,1: 14,1: 16$ & $1: 1,1: 2,1: 3,1: 4,1: 5,1: 6,1: 7$ \\
\hline the Earth tides & $1: 2$ & $1: 2$ & $1: 1,1: 2,1: 3,1: 4$ \\
\hline the ocean tides & $1: 2$ & $1: 1,1: 2,1: 3,1: 4,1: 5,1: 6,1: 8,1: 21$ & $1: 1,1: 2,1: 3,1: 41: 6$ \\
\hline $\begin{array}{c}\text { the gravitation } \\
\text { of the Moon }\end{array}$ & $1: 2,1: 6$ & $1: 112.5,1: 209,1: 225$ & $1: 1,1: 2,1: 3,1: 4,1: 5,1: 6,1: 7$ \\
\hline $\begin{array}{c}\text { the gravitation } \\
\text { of the Sun }\end{array}$ & - & $1: 2,1: 4,1: 14,1: 18$ & $1: 1,1: 2,1: 3,1: 4$ \\
\hline $\begin{array}{c}\text { the gravitation } \\
\text { of the Venus }\end{array}$ & - & - & $1: 1,1: 2,1: 3,1: 4,1: 5,1: 6,1: 8$ \\
\hline $\begin{array}{c}\text { the relativity } \\
\text { effects }\end{array}$ & $1: 2$ & $\begin{array}{c}1: 1,1: 2,1: 3,1: 4,1: 5,1: 13,1: 15, \\
1: 17,1: 18,1: 19,1: 168,1: 216\end{array}$ & $1: 1,1: 2,1: 3,1: 4$ \\
\hline
\end{tabular}

Table 8. Noticed resonances of the periodic components of the chosen satellite accelerations with respect to the 30-day period (close to the Moon's synodic period), the Earth's rotation period and the $86.441 \mathrm{~min}$. period (close to the satellite orbital period).

rotation period was seen. The occurrence of the resonances with respect to the aforementioned periods clearly indices on the dependence of regarded accelerations on the satellite orbital period, the Earth's rotation period, the Moon's synodic period. However, no resonances were constated for the acceleration generated by the gravitation of the Sun with respect to the 30day period and for the acceleration due to the Venus with respect to the 30 -day period and the Earth's rotation period (Table 8).

\section{RESULTS FOR SELECTED ORBITAL ELEMENTS}

The clearly domination of the component $\sim 44.77 \mathrm{~min}$. with the amplitude $\sim 3.84 \mathrm{~km}$ is a characteristic feature of the amplitude PSD for the semi-major axis (Figure 8). Two other components can be also distinguished: the component $\sim 30.49$ min. with the amplitude $1.37 \mathrm{E}-02 \mathrm{~km}$ and the component 15.00 days with the amplitude $\sim 1.26 \mathrm{E}-02 \mathrm{~km}$ (Table 9). The amplitude of the main periodic component with the period $\sim 44.77 \mathrm{~min}$. (close to half the satellite orbital period) is two orders of magnitude greater than the amplitude of the aforementioned components.

For the 30-day orbital arc, the averaged semi-major axis is equal to about $6624.98 \mathrm{~km}$ and the sigma has the value of about $6.94 \mathrm{~km}$ (Table 9). 


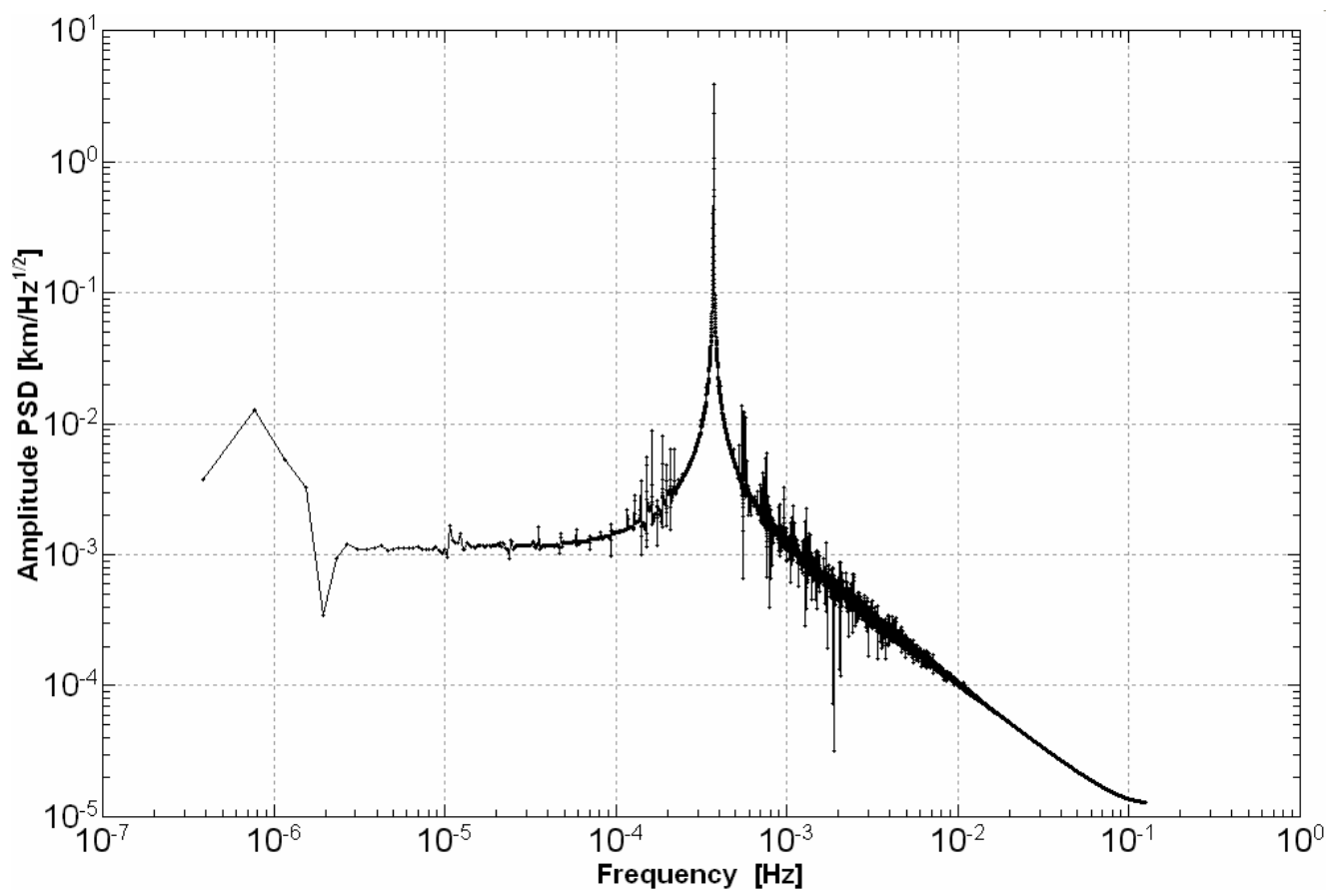

Fig. 8. Amplitude PSD of the semi-major axis for the 30 day orbital arc.

Sampling interval: 4 seconds.

\begin{tabular}{|c|c|c|}
\hline Amplitude $[\mathrm{km}]$ & Frequency $[\mathrm{Hz}]$ & Period \\
\hline 3.8485 & $3.7230 \mathrm{E}-04$ & $44.7668 \mathrm{~min}$. \\
\hline $1.3695 \mathrm{E}-02$ & $5.4668 \mathrm{E}-04$ & 30.4869 min. \\
\hline $1.2620 \mathrm{E}-02$ & $7.7160 \mathrm{E}-07$ & 15.0000 days \\
\hline $8.7678 \mathrm{E}-03$ & $1.6281 \mathrm{E}-03$ & 102.3697 min. \\
\hline $7.9927 \mathrm{E}-03$ & $1.8634 \mathrm{E}-04$ & $89.4410 \mathrm{~min}$. \\
\hline $6.3812 \mathrm{E}-03$ & $2.0910 \mathrm{E}-04$ & 79.7048 min. \\
\hline 6.3493E-03 & $2.2068 \mathrm{E}-04$ & 75.5245 min. \\
\hline Average: 6624.9753 km sigma: $6.9452 \mathrm{~km}$ \\
\hline
\end{tabular}

Table 9: Selected amplitudes, frequencies and periods of the semi-major axis variations. At the last line, the average and sigma of this orbital element in the time

Similarly to the amplitude PSD for the semi-major axis, the dominant component in the case of the eccentricity has the period about $44.77 \mathrm{~min}$. and its amplitude is equal to about 2.48E-04 (Figure 9). The components with the periods $\sim 29.85 \mathrm{~min}$. and $\sim 89.44 \mathrm{~min}$. (close to the satellite orbital period) have the amplitudes with the same order of magnitude as for the dominant component (Table 10). There is a group of many periodic components in the frequency range between $\sim 1 \mathrm{E}-03 \mathrm{~Hz}$ and $\sim 4 \mathrm{E}-02 \mathrm{~Hz}$. The decreasing trend of amplitude for the components from this group can be seen (Figure 9).

In this case the average for the 30-day orbital arc is $\sim 1.48 \mathrm{E}-03$ and the sigma is $\sim 7.99$ E-04 (Table 10). The averaged eccentricity is close to the initial one (1.00E-03). 


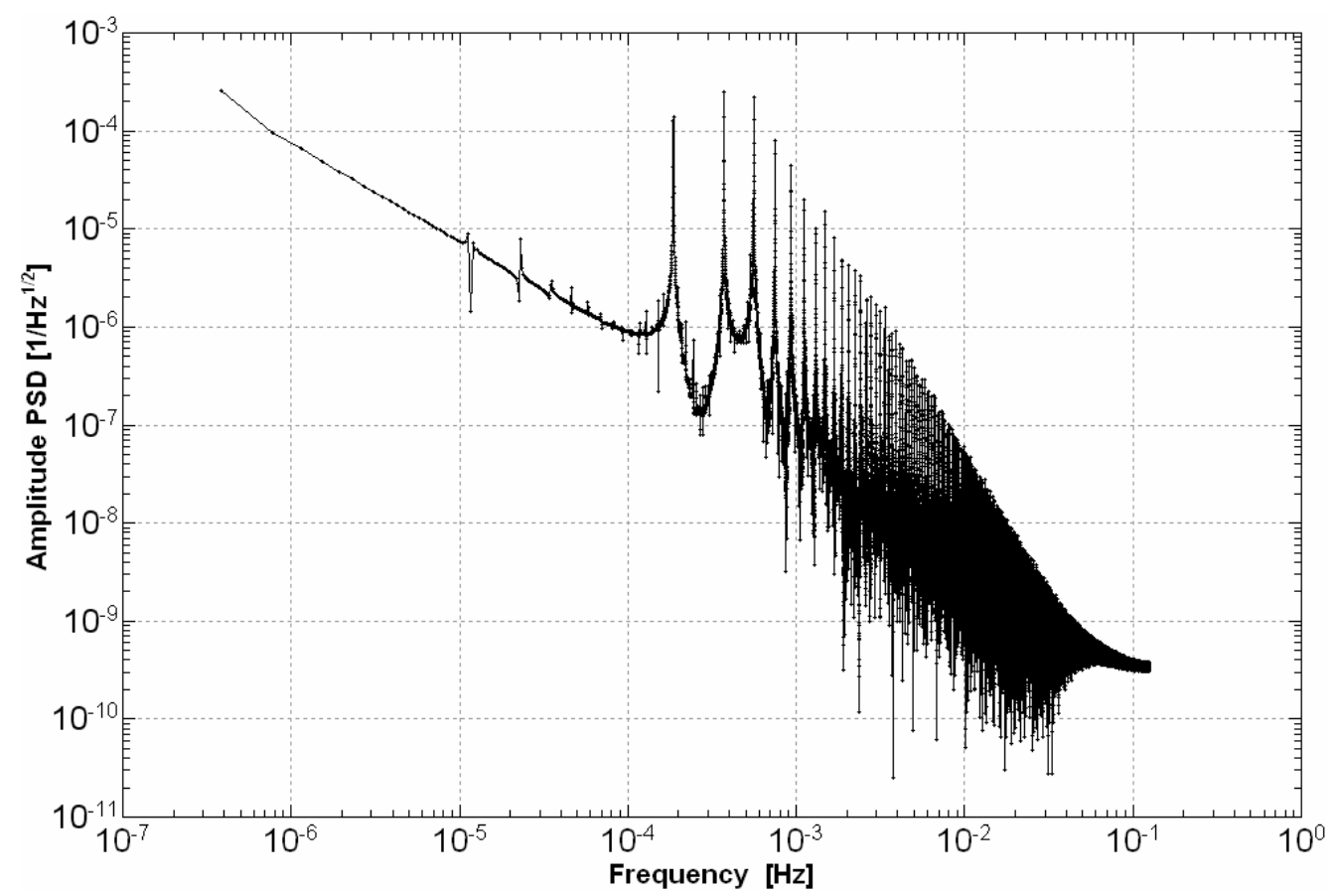

Fig. 9. Amplitude PSD of the eccentricity for the 30 day orbital arc.

Sampling interval: 4 seconds.

\begin{tabular}{|c|c|c|}
\hline Amplitude & Frequency [Hz] & Period \\
\hline $2.4807 \mathrm{E}-04$ & $3.7230 \mathrm{E}-04$ & $44.7668 \mathrm{~min}$. \\
\hline $2.2028 \mathrm{E}-04$ & $5.5826 \mathrm{E}-04$ & $29.8549 \mathrm{~min}$. \\
\hline $1.3751 \mathrm{E}-04$ & $1.8634 \mathrm{E}-04$ & $89.4410 \mathrm{~min}$. \\
\hline $7.8718 \mathrm{E}-05$ & $7.4421 \mathrm{E}-04$ & $22.3950 \mathrm{~min}$. \\
\hline $4.3903 \mathrm{E}-05$ & $9.3055 \mathrm{E}-04$ & $17.9104 \mathrm{~min}$. \\
\hline $1.9833 \mathrm{E}-05$ & $1.1169 \mathrm{E}-03$ & $14.9223 \mathrm{~min}$. \\
\hline 1.0054E-05 & $1.3028 \mathrm{E}-03$ & $12.7924 \mathrm{~min}$. \\
\hline Average: $1.4840 \mathrm{E}-03$ sigma: $7.9916 \mathrm{E}-04$ \\
\hline
\end{tabular}

Table 10: Selected amplitudes, frequencies and periods of the eccentricity variations. At the last line, the average and sigma of this orbital element in the time domain.

Figure 10 presents the amplitude PSD of the inclination with the main periodic component $\sim 44.77 \mathrm{~min}$. (similarly for two pervious cases, i.e. for semi-major axis and eccentricity) and the amplitude $\sim 1.89 \mathrm{E}-03$ degree. The next two components have the amplitudes about 1.21E03 degree, 3.96E-04 degree and the periods 12.0 hours, 6.0 days, respectively (Table 11).

The averaged inclination for the 30-day orbital arc is equal to about 96.51 degrees, which is close to the initial value (96.50 degrees). The sigma with the value $\sim 5.22 \mathrm{E}-03$ degree has the same order of magnitude as for the main periodic component (Table 11). 


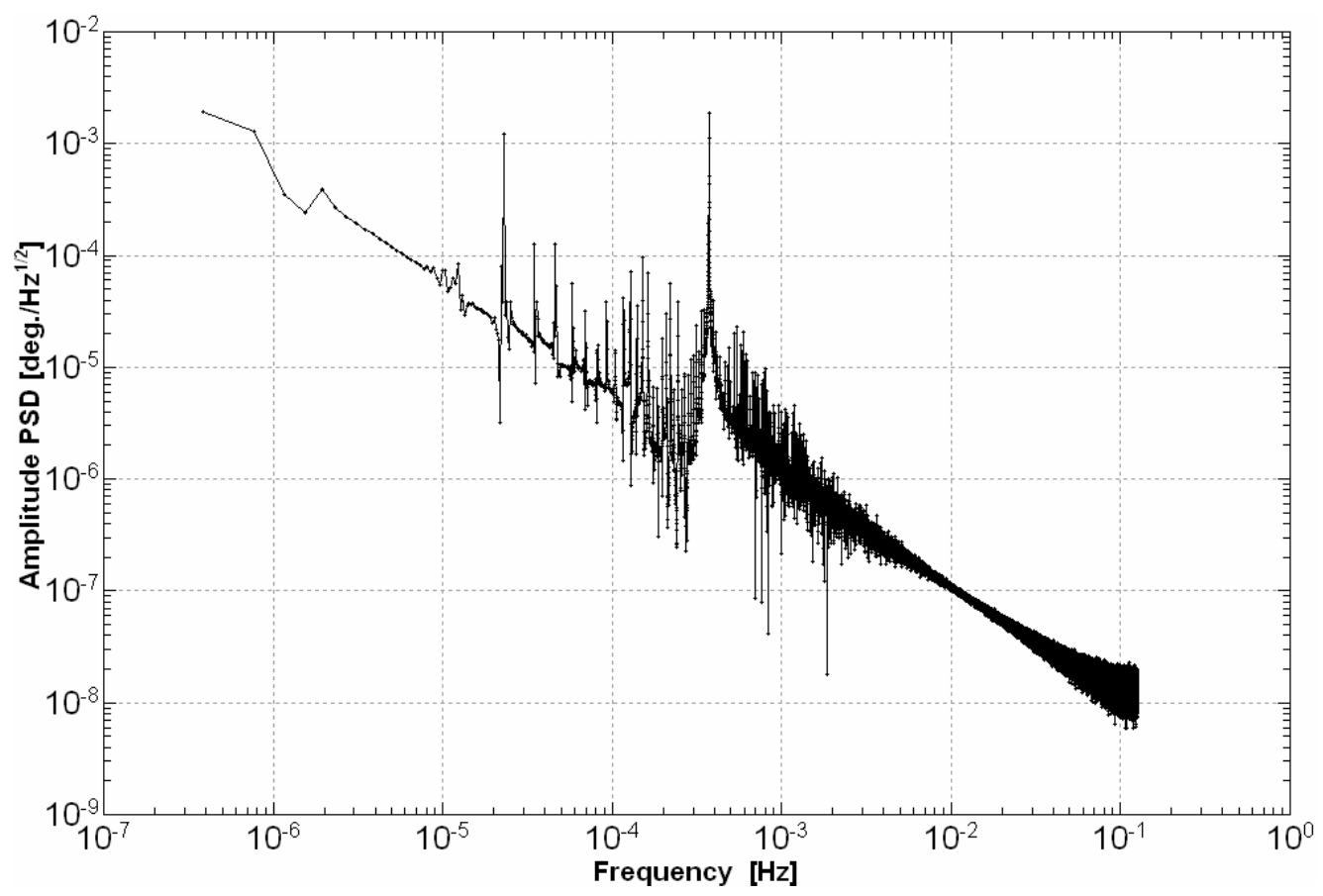

Fig. 10. Amplitude PSD of the inclination for the 30 day orbital arc. Sampling interval: 4 seconds.

\begin{tabular}{|c|c|c|}
\hline Amplitude [degrees] & Frequency [Hz] & Period \\
\hline $1.8932 \mathrm{E}-03$ & $3.7230 \mathrm{E}-04$ & $44.7668 \mathrm{~min}$. \\
\hline $1.2105 \mathrm{E}-03$ & $2.3148 \mathrm{E}-05$ & $12.0000 \mathrm{~h}$ \\
\hline $3.9583 \mathrm{E}-04$ & $1.9290 \mathrm{E}-06$ & 6.0000 days \\
\hline $1.2650 \mathrm{E}-04$ & $3.4722 \mathrm{E}-05$ & $7.9992 \mathrm{~h}$ \\
\hline $1.2516 \mathrm{E}-04$ & $4.6296 \mathrm{E}-05$ & $6.0000 \mathrm{~h}$ \\
\hline $9.6847 \mathrm{E}-05$ & $1.5123 \mathrm{E}-04$ & $1.8367 \mathrm{~h}$ \\
\hline $7.2330 \mathrm{E}-05$ & $1.2809 \mathrm{E}-04$ & $2.1687 \mathrm{~h}$ \\
\hline Average: 96.5127 deg. sigma: $5.2182 \mathrm{E}-03$ deg. \\
\hline
\end{tabular}

Table 11: Selected amplitudes, frequencies and periods of the inclination variations. At the last line, the average and sigma of this orbital element in the time domain.

The amplitude PSD for the argument of perigee is given in Figure 11. The component $\sim 29.85 \mathrm{~min}$. has the highest amplitude 23.48 degrees. Three successive components are characterized by the periods about $89.63 \mathrm{~min} ., 17.91 \mathrm{~min} ., 44.77 \mathrm{~min}$. and by the amplitudes about 18.99, 14.84, 9.15 degrees, respectively (Table 12). Figure 11 shows many periodic components placed in the range between $\sim 1.0 \mathrm{E}-03$ and $1.1 \mathrm{E}-01 \mathrm{~Hz}$.

For the argument of perigee, the average along the 30-day orbital arc, near value 165.22 degrees, differs considerably from the initial value 0.00 degree. This may by caused by a numerical noise, which results from the difficult computational conditioning with the relatively small initial eccentricity 0.001 . The standard deviation (sigma) is equal to $\sim 72.43$ degrees and it is also connected to the aforementioned computational conditioning. 


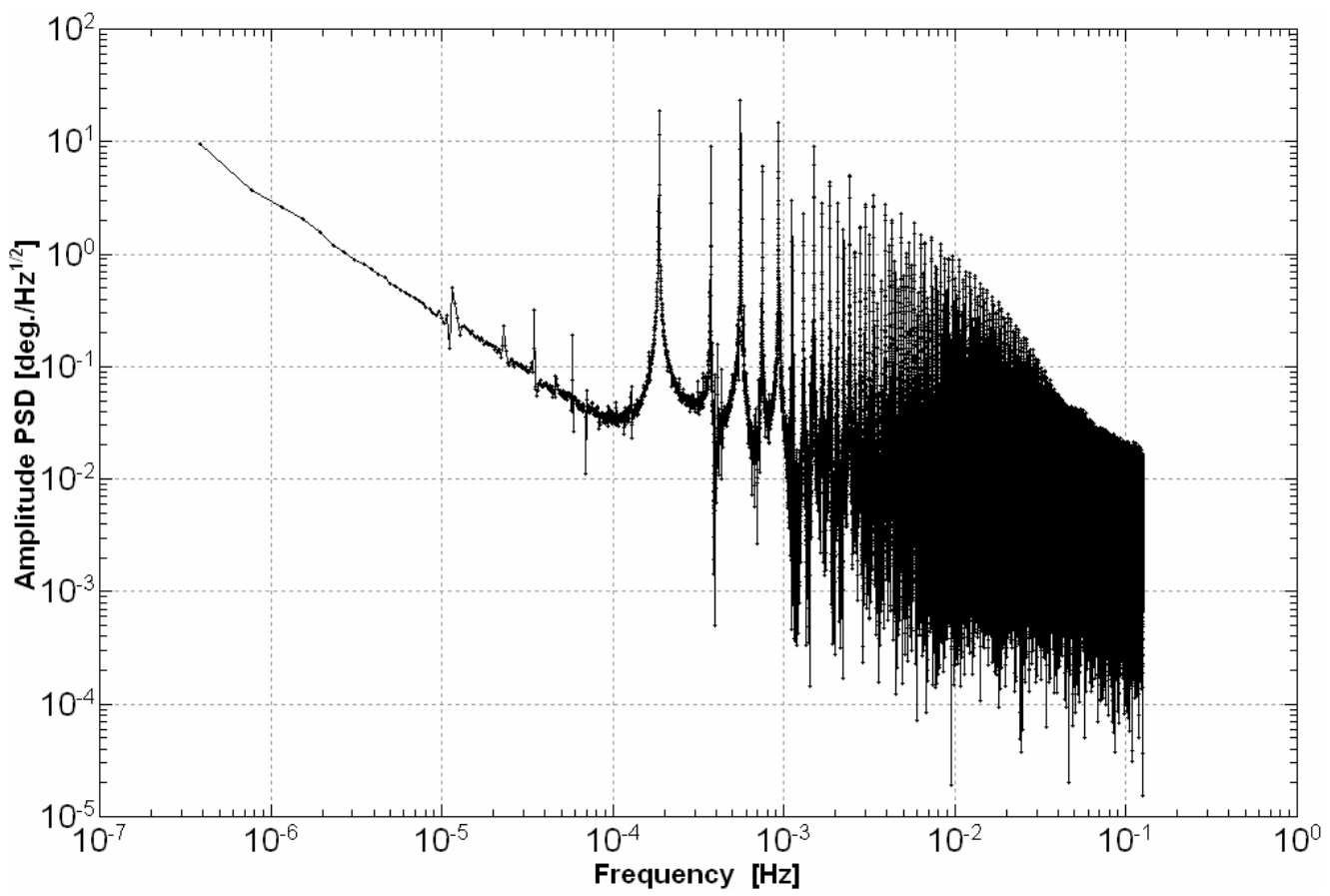

Fig. 11. Amplitude PSD of the argument of perigee for the 30 day orbital arc. Sampling interval: 4 seconds.

\begin{tabular}{|c|c|c|}
\hline Amplitude [degrees] & Frequency [Hz] & Period \\
\hline 23.4800 & $5.5826 \mathrm{E}-04$ & 29.8549 min. \\
\hline 18.9938 & $1.8596 \mathrm{E}-04$ & 89.6266 min. \\
\hline 14.8383 & $9.3055 \mathrm{E}-04$ & 17.9104 min. \\
\hline 9.1536 & $3.7230 \mathrm{E}-04$ & 44.7668 min. \\
\hline 8.9791 & $1.4888 \mathrm{E}-03$ & 11.1946 min. \\
\hline 5.9531 & $7.4421 \mathrm{E}-04$ & 22.3950 min. \\
\hline 5.0235 & $2.4190 \mathrm{E}-03$ & 6.8899 min. \\
\hline Average: 165.2231 deg. sigma: 72.4320 deg. \\
\hline
\end{tabular}

Table 12: Selected amplitudes, frequencies and periods of the variations of the argument of perigee. At the last line, the average and sigma of this orbital element in the time domain

For the right ascension of ascending node, a specific shape of the amplitude PSD can be seen in Figure 12. It is the drooping Fourier background with one weak component. This component can be described by the period about $44.77 \mathrm{~min}$ (close to half the satellite orbital period) and the amplitude near value 5.84E-03 degree. In this case, the secular changes of the right ascension of ascending node are modulated by the aforementioned weak periodic component.

The computed average for the 30-day orbital arc is equal to $\sim 59.71$ degrees with the sigma $\sim 8.49$ degrees. The difference between this average and the initial value ( 45.0 degrees) is caused mainly by the mentioned secular changes of the right ascension of ascending node along the regarded 30-day orbital arc. 


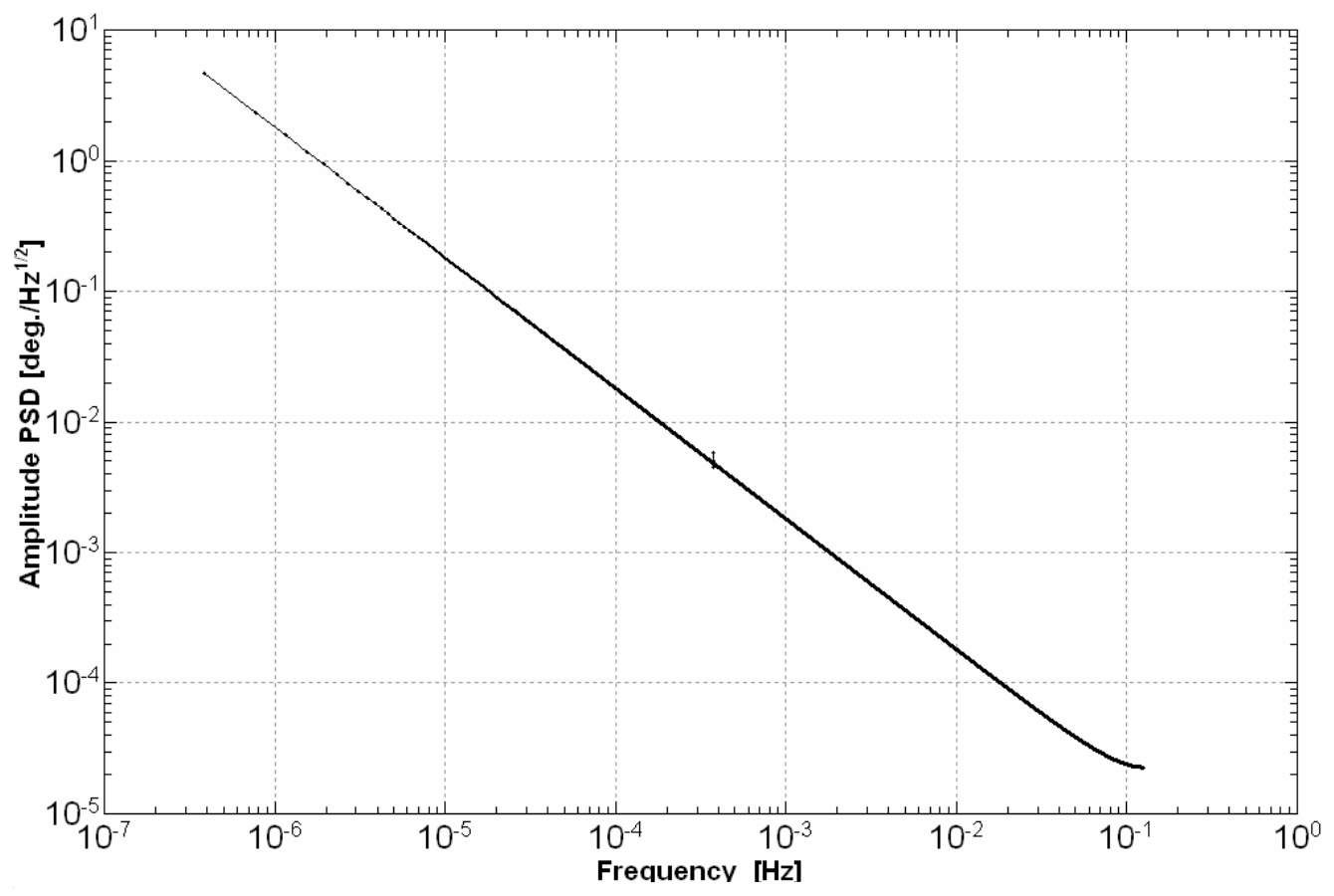

Fig. 12. Amplitude PSD of the right ascension of ascending node for the 30 day orbital arc. Sampling interval: 4 seconds.

Similarly as for the accelerations, the observed resonances of the periodic components of orbital elements with respect to the 30-day period, the Earth's rotation period and the 89.441 min. period are presented in Table 13. Most resonances were noticed for the Earth's rotation period. They are included in the ranges: from 1:1 to 1:216 (for the semi-major axis), from 1:1 to $1: 21$ (for the eccentricity), from 1:1 to $1: 19$ (for the inclination) and from 1:1 to $1: 11$ (for the argument of perigee). The numerous resonances with respect to the $89.441 \mathrm{~min}$. period are visible for the eccentricity (from 1:1 to 1:15) and for the argument of perigee (from 1:1 to $1: 31)$. For the remaining elements, the resonances with respect to the same period are less numerous; $1: 1,1: 2,1: 3,1: 9$ for the semi-major axis, 1:2, 1:3 for the inclination and only $1: 2$ for the right ascension of ascending node. Only two resonances were noticed with respect to the 30-day period; 1:2 for the semi-major axis and 1:5 for the inclination. For the right ascension of ascending node, one resonance 1:2 with the $89.441 \mathrm{~min}$. period can be seen in Table 13. 
Table 13. Noticed resonances of the periodic components of the chosen orbital elements with respect to the 30-day period (close to the Moon's synodic period), the Earth's rotation period and the $86.441 \mathrm{~min}$. period (close to the satellite orbital period).

\begin{tabular}{|c|c|c|c|}
\hline \multirow{2}{*}{ Orbital element } & \multicolumn{3}{|c|}{ Resonance with respect to } \\
\cline { 2 - 4 } & $\begin{array}{c}\text { the 30-day } \\
\text { period }\end{array}$ & \multicolumn{1}{|c|}{ the Earth's rotation period } & the 89.441 min. period \\
\hline Semi-major axis & $1: 2$ & $\begin{array}{l}1: 1,1: 3,1: 4,1: 5,1: 7,1: 8,1: 10, \\
1: 11,1: 12,1: 13,1: 14,1: 16,1: 17, \\
1: 18,1: 19,1: 168,1: 216\end{array}$ & $1: 1,1: 2,1: 3,1: 9$ \\
\hline Eccentricity & - & $\begin{array}{l}1: 1,1: 2,1: 3,1: 4,1: 5,1: 6,1: 10, \\
1: 11,1: 13,1: 14,1: 21\end{array}$ & $\begin{array}{l}1: 1,1: 2,1: 3,1: 4,1: 5,1: 6,1: 7, \\
1: 8,1: 9,1: 10,1: 11,1: 12,1: 13, \\
1: 15\end{array}$ \\
\hline Inclination & $1: 5$ & $\begin{array}{l}1: 1,1: 2,1: 3,1: 4,1: 5,1: 8,1: 11, \\
1: 13,1: 14,1: 19\end{array}$ & $1: 2,1: 3$ \\
\hline $\begin{array}{c}\text { Argument } \\
\text { of perigee }\end{array}$ & - & $1: 1,1: 2,1: 3,1: 4,1: 5,1: 9,1: 11$ & $\begin{array}{l}1: 1,1: 1,1: 3,1: 1: 4,1: 5,1: 6,1: 7,11,1: 13,1: 16, \\
1: 18,1: 21,1: 21,1: 26,1: 31\end{array}$ \\
\hline $\begin{array}{c}\text { Right ascension } \\
\text { of ascending } \\
\text { node }\end{array}$ & - & & $1: 2$ \\
\hline
\end{tabular}

\section{SUMMARY}

The assumed goal of this work was realized by the obtained spectra of the selected accelerations and orbital elements of the GOCE satellite for the 30-day orbital arc with the sampling interval of 4 seconds. These spectra contain numerous periodic components. The dominating and distinguishing components have the following periods:

- $89.4410 \mathrm{~min}$. (close to the satellite orbital period); in the accelerations generated by: the geopotential, the Moon, the Sun, the Venus, the relativity effects, in the semi-major axis and in the eccentricity,

- $89.6266 \mathrm{~min}$. (close to the satellite orbital period); in the accelerations due to: the geopotential, the Earth tides, the ocean tides, the Moon, the Sun, the Venus and in the argument of perigee,

- $44.7668 \mathrm{~min}$. (the components with this period are especially strong; the period close to half the satellite orbital period); in the accelerations due to: the geopotential, the Earth tides, the Moon, the Sun, the Venus, the relativity effects and in the orbital elements: semi-major axis, eccentricity, inclination, argument of perigee, right ascension of ascending node,

- close to 30 min.; in the accelerations induced by: the geopotential, the Earth tides, the ocean tides, the Moon, the Venus, the relativity effects and in the orbital elements: semi-major axis, eccentricity, inclination, argument of perigee,

- close to 22 min.; in the accelerations generated by: the geopotential, the Earth tides, the ocean tides, the Moon, the Sun, the Venus, the relativity effects and in the orbital elements: eccentricity, argument of perigee,

- 15.0 days.; in the accelerations generated by: the geopotential, the Earth tides, the ocean tides, the Moon, the relativity effects and in the semi-major axis. 
Besides, the components with the periods connected to the Earth's rotation period also occurred in the majority spectra.

Numerous resonances were identified with respect to:

- the $89.441 \mathrm{~min}$. period (close to the satellite orbital period); the resonances included in the range from $1: 1$ to $1: 31$,

- the Earth's rotation period; the resonances included in the range from 1:1 to 1:225,

- the 30-day period (close to the Moon's synodic period); the resonances included in the range from $1: 2$ to $1: 6$.

It can be also noticed that the component with the period $89.6266 \mathrm{~min}$. (close to the satellite orbital period) is in the resonance near value 16:1 with the Earth's rotation period.

The obtained results can be useful for an analysis of the resonance effects of the GOCE orbit in terms of the amplitudes, periods and frequencies. Such analysis can be performed in a preparation phase of the gravity field recovery process.

\section{REFERENCES}

Anderson J. D., Laing P.A., Lau E. L., et al. Study of the anomalous acceleration of Pioneer 10 and 11. Phys. Rev. D65 082004, 2002.

Baur O., Grafarend W. Orbital rotations of a satellite. Case study: GOCE. Artificial Satellites, Vol. 40, No. 2 - 2005.

Bock H., Jäggi A., Svehla D., et al. Precise Orbit Determination for the GOCE Satellite Using GPS. Committee on Space Research 36th COSPAR Scientific Assembly Beijing, China, July 16-23, 2006.

Ditmar P., Klees R. A Method to Compute the Earth's Gravity Field from SGG/SST data to be Acquired by the GOCE Satellite. Delft University Press, 2002.

Ditmar P., Visser P., Klees R. On the joint inversion of SGG and SST data from the GOCE mission. Advances in Geosciences. 1:87-94, 2003.

Drinkwater, M.R., Floberghagen, R., Haagmans, R., et al. GOCE: ESA's First Earth Explorer Core Mission. Space Science Reviews 00: 1-14, 2003.

Drożyner A. Determination of Orbits with Toruń Orbit Processor System. Adv. Space Res., vol. 16, No. 2, 1995.

ESA. ESA's Gravity Mission - GOCE Brochure (revised), 2006.

ESA. Gravity Field and Steady-State Ocean Circulation Mission, ESA SP-1233(1). Report for mission selection of the four candidate Earth Explorer missions, 1999.

Johannessen J. A., Balmino G., Le Provost C., et al. The European Gravity Field and Steady-State Ocean Circulation Explorer Satellite Mission Its Impact on Geophysics. Surveys in Geophysics; 24(4) : 339-386, July 2003.

Laing P. A. Implementation of J2000.0 reference frame in CHASMP. The Aerospace Corporation's Internal Memorandum \# 91(6703)-1. January 28, 1991.

Lemoine F., Kenyon S., Factor J., et al. The Development of the Joint NASA GSFC and the National Imagery and Mapping Agency (NIMA) Geopotential Model EGM96. Report No.206861, 1998. 
Melbourne W., et al. Project MERIT Standards, Circ. 167, U.S. Naval Observatory, Washington, D.C., 1983.

Mégie G., Readings C. J. The Earth Explorer Missions - Current Status. Earth Observation Quarterly No. 66, 2000.

Rebhan H., Aguirre M., Johannessen J. The Gravity Field and Steady-State Ocean Circulation Explorer Mission - GOCE, ESA Earth Observation Quarterly 66: 6-11, 2000.

Visser P.N.A.M., IJssel J., Koop R., Klees R. Exploring gravity field determination from orbit perturbations of the European Gravity Mission GOCE. Journal of Geodesy 75: 89-98, 2001 .

Visser P., Ijssel J., Helleputte T., et al. Rapid and Precise Orbit Determination for the GOCE satellite. 3rd GOCE user workshop, ESA ESRIN, 6-8 November 2006.

Received: 2009-02-27,

Reviewed: 2009-05-07, by S. Schillak,

Accepted: 2009-07-10. 